\title{
SHEA Neonatal Intensive Care Unit (NICU) White Paper Series: Practical approaches for the prevention of central-line-associated bloodstream infections
}

\author{
Martha Muller MD², Kristina A. Bryant MD², Claudia Espinosa MD, MSC ${ }^{5}$, Jill A. Jones MS, APRN, NNP-BC \\ Caroline Quach MD, MSc, FRCPC 7,8 , Jessica R. Rindels MBA, BSN, RN, CIC , Dan L. Stewart MD ${ }^{10,11}$, \\ Kenneth M. Zangwill MD ${ }^{12}$ and Pablo J. Sánchez MD ${ }^{13,14}$ \\ ${ }^{1}$ Pediatric Infectious Disease, University of New Mexico School of Medicine, Albuquerque, New Mexico, United States, ${ }^{2}$ UNM Health Sciences, Albuquerque, New \\ Mexico, United States, ${ }^{3}$ Pediatric Infectious Diseases, University of Louisville, Louisville, Kentucky, United States, ${ }^{4}$ Norton Children's Hospital, Louisville, \\ Kentucky, United States, ${ }^{5}$ Pediatric Infectious Diseases, University of South Florida Morsani College of Medicine, Tampa, Florida, United States, ${ }^{6} \mathrm{Nationwide}$ \\ Children's Hospital, Columbus, Ohio, United States, ${ }^{7}$ Departments of Microbiology, Infectious Diseases and Immunology and Pediatrics, University of Montreal, \\ Montreal, Québec, Canada, ${ }^{8} \mathrm{Clinical}$ Department of Laboratory Medicine, CHU Sainte-Justine, Québec, Canada, ${ }^{9} \mathrm{Children}$ 's Mercy Hospital, Kansas City, Missouri, \\ United States, ${ }^{10}$ Norton Children's Hospital, Louisville, Kentucky, United States, ${ }^{11}$ University of Louisville School of Medicine, Louisville, Kentucky, United States, \\ ${ }^{12}$ Division of Pediatric Infectious Diseases and Department of Infection Prevention and Control, Harbor-UCLA Medical Center, Torrance, California, United States, \\ ${ }^{13}$ Divisions of Neonatology and Pediatric Infectious Diseases, Department of Pediatrics, Nationwide Children's Hospital, Columbus, Ohio, United States and \\ ${ }^{14}$ Center for Perinatal Research, Abigail Wexner Research Institute at Nationwide Children's Hospital, The Ohio State University College of Medicine, Columbus, \\ Ohio, United States
}

\begin{abstract}
This document is part of the "SHEA Neonatal Intensive Care Unit (NICU) White Paper Series." It is intended to provide practical, expert opinion, and/or evidence-based answers to frequently asked questions about CLABSI detection and prevention in the NICU. This document serves as a companion to the CDC Healthcare Infection Control Practices Advisory Committee (HICPAC) Guideline for Prevention of Infections in Neonatal Intensive Care Unit Patients. Central line-associated bloodstream infections (CLABSIs) are among the most frequent invasive infections among infants in the NICU and contribute to substantial morbidity and mortality. Infants who survive CLABSIs have prolonged hospitalization resulting in increased healthcare costs and suffer greater comorbidities including worse neurodevelopmental and growth outcomes. A bundled approach to central line care practices in the NICU has reduced CLABSI rates, but challenges remain. This document was authored by pediatric infectious diseases specialists, neonatologists, advanced practice nurse practitioners, infection preventionists, members of the HICPAC guideline-writing panel, and members of the SHEA Pediatric Leadership Council. For the selected topic areas, the authors provide practical approaches in question-and-answer format, with answers based on consensus expert opinion within the context of the literature search conducted for the companion HICPAC document and supplemented by other published information retrieved by the authors. Two documents in the series precede this one: "Practical approaches to Clostridioides difficile prevention" published in August 2018 and "Practical approaches to Staphylococcus aureus prevention," published in September 2020.
\end{abstract}

(Received 22 February 2022; accepted 23 February 2022; electronically published 4 March 2022)

Central-line-associated bloodstream infections (CLABSIs) are among the most frequent invasive infections among infants in the NICU, and they contribute to substantial morbidity and mortality. Infants who develop CLABSIs have prolonged hospitalizations, resulting in increased healthcare costs; these infants also suffer greater comorbidities, including worse neurodevelopmental and growth outcomes. ${ }^{1-3} \mathrm{~A}$ bundled approach to central-line care practices in the NICU has reduced CLABSI rates significantly, ${ }^{4-6}$ but challenges remain. A cross-sectional study using 2013-2018 Centers for Disease Control and Prevention (CDC) surveillance

Corresponding author: Kristina A. Bryant, MD, E-mail: kristina.bryant@louisville.edu Cite this article: Muller M, Bryant KA, Espinosa C, et al. (2023). SHEA Neonatal Intensive Care Unit (NICU) White Paper Series: Practical approaches for the prevention of central-line-associated bloodstream infections. Infect Control Hosp Epidemiol, 44: 550-564, doi: 10.1017/ice.2022.53 data from 132 NICUs that report to the National Healthcare Safety Network (NHSN) suggested that previous improvements in CLABSI rates have plateaued. ${ }^{7}$ During the study period, CLABSI rates remained stable, with mean rates of 1.56 CLABSIs per 1,000 central venous catheter (CVC) days in NICU patients with birth weights $\leq 1,500$ grams and 0.72 CLABSIs per 1,000 CVC days for those with birth weights $>1,500$ grams. Infants in the NICU have certain unmodifiable risk factors for infection (eg, an immature immune system), and they require life-sustaining invasive procedures (eg, endotracheal intubation and umbilical, central venous and arterial catheterization) that are essential for respiratory and nutritional support. Importantly, these infants often suffer from disruption in skin and intestinal integrity that may contribute to translocation of pathogens resulting in a diagnosis of CLABSI. Nevertheless, adherence to proper insertion 
techniques and management of the $\mathrm{CVC}$ can reduce CLABSI rates, even among the highest-risk infants. The $\mathrm{CDC}$ has recommended elements of insertion and maintenance bundles for all patients, although the nuances of care for NICU patients are not included (Table 3$).{ }^{8}$ This white paper provides clinicians with practical guidance on the implementation of strategies to prevent CLABSIs in NICU patients, including those strategies above and beyond the elements suggested by CDC.

\section{Intended use}

The Society for Healthcare Epidemiology of America (SHEA) intends for this document to serve as a companion to the CDC Healthcare Infection Control Practices Advisory Committee (HICPAC) Guideline for Prevention of Infections in Neonatal Intensive Care Unit Patients, ${ }^{9}$ and to provide practical, expert opinions, and/or evidence-based answers to frequently asked questions about CLABSI detection and prevention in the NICU. This document is not a comprehensive compilation of infection prevention strategies recommended for NICUs. Hand hygiene, environmental cleaning and disinfection, infection prevention education for family members and caregivers, and other core practices recommended by the CDC for all healthcare settings are essential to CLABSI prevention and are detailed elsewhere https://www.cdc. gov/hicpac/recommendations/core-practices.html.

The published literature related to the questions presented herein is not sufficient to meet Grading of Recommendations Assessment, Development and Evaluation (GRADE) standards ${ }^{9,10}$; therefore, the authors provide no evidence grading, and answers incorporate experts' clinical experience. No guideline, expert guidance, or white paper can anticipate all situations. This document is meant to serve as an adjunct to individual judgment by qualified professionals. In general, these recommendations apply to nonoutbreak settings. Healthcare personnel (HCP) may implement additional measures during an outbreak or other special clinical scenarios.

\section{Methods}

This document has been developed by pediatric infectious diseases specialists, neonatologists, advanced practice nurse practitioners, infection preventionists, and members of the HICPAC guideline-writing panel, as well as members of the SHEA Pediatric Leadership Council, to identify and address practical questions anticipated from practitioners and infection prevention professionals. This document is part of the "SHEA Neonatal Intensive Care Unit (NICU) White Paper Series." Two documents in the series precede this one: "Practical approaches to Clostridioides difficile prevention" published in August $2018^{11}$ and "Practical approaches to Staphylococcus aureus prevention," published in September 2020. ${ }^{12}$

Unlike the SHEA expert guidance format, this document is not based on a systematic literature search. Instead, for the selected topic areas, the authors provide practical approaches in question-and-answer format, with answers based on consensus expert opinion within the context of the literature search conducted for the companion HICPAC document and supplemented by other published information retrieved by the authors.

The full white paper series is overseen by a group of experts in pediatrics, including pediatric infectious diseases specialists,
Table 1. Abbreviations

\begin{tabular}{|c|c|}
\hline AAP & American Academy of Pediatrics \\
\hline $\begin{array}{l}\text { AAP/ } \\
\text { SOID }\end{array}$ & $\begin{array}{l}\text { American Academy of Pediatrics Section on Infectious } \\
\text { Diseases }\end{array}$ \\
\hline $\mathrm{AHA}$ & American Hospital Association \\
\hline APIC & $\begin{array}{l}\text { Association for Professionals in Infection Control and } \\
\text { Epidemiology }\end{array}$ \\
\hline $\mathrm{CDC}$ & US Centers for Disease Control and Prevention \\
\hline $\mathrm{CHG}$ & Chlorhexidine gluconate \\
\hline $\mathrm{Cl}$ & Confidence Interval \\
\hline CLABSI & Central-line-associated bloodstream infection \\
\hline CVC & Central venous catheter \\
\hline EBM & Evidence-based medicine \\
\hline FDA & US Food and Drug Administration \\
\hline $\mathrm{HCP}$ & Healthcare personnel \\
\hline IDSA & Infectious Diseases Society of America \\
\hline $\mathrm{kg}$ & Kilogram \\
\hline $\mathrm{mg}$ & Milligram \\
\hline $\mathrm{mL}$ & Milliliter \\
\hline NANN & National Association of Neonatal Nurses \\
\hline NICU & Neonatal intensive care unit \\
\hline NS & Normal saline \\
\hline OR & Odds Ratio \\
\hline $\mathrm{PICC}$ & Peripherally inserted central catheter \\
\hline PIDS & Pediatric Infectious Diseases Society \\
\hline SHEA & Society for Healthcare Epidemiology of America \\
\hline TPN & Total parenteral nutrition \\
\hline VAT & Vascular access team \\
\hline VON & Vermont Oxford Network \\
\hline
\end{tabular}

neonatologists, advanced practice nurse practitioners, and infection preventionists, convened by SHEA, called the NICU Advisory Panel (see the Acknowledgments). The NICU Advisory Panel members serve as representatives for the following organizations: the American Hospital Association (AHA), the American Academy of Pediatrics (AAP), the Association for Professionals in Infection Control and Epidemiology (APIC), the Infectious Diseases Society of America (IDSA), The Joint Commission, the National Association of Neonatal Nurses (NANN), the Pediatric Infectious Diseases Society (PIDS), and the Vermont Oxford Network (VON). This document was reviewed by the NICU Advisory Panel member organizations, the SHEA Guidelines Committee, and the SHEA Publications Committee.

This white paper has been endorsed by SHEA, AHA, APIC, IDSA, The Joint Commission, NANN, and PIDS.

A list of abbreviations, including organization acronyms, is provided in Table 1.

\section{Authors}

The authors include current and past members of the SHEA Guidelines Committee and the SHEA Pediatric Leadership Council, and representation from AAP and APIC. All authors 
Table 2. Questions and Recommendations

\begin{tabular}{|c|c|c|}
\hline$\#$ & Question & Answer \\
\hline 1 & $\begin{array}{l}\text { Which NICU patients are likely to benefit from use of } \\
\text { chlorhexidine (CHG) skin antisepsis for CVC insertion } \\
\text { and maintenance? }\end{array}$ & $\begin{array}{l}\text { - Skin antisepsis should occur for all infants in the NICU and optimally should } \\
\text { be performed with a CHG-containing product. } \\
\text { - For infants } \geq 8 \text { weeks of age } 2 \% \text { CHG in } 70 \% \text { alcohol should be used. } \\
\text { - For infants }<8 \text { weeks of age, the authors' clinical experience shows that a } \\
\text { CHG-containing product may be used safely. Additionally, FDA has stated } \\
\text { that CHG may be "[used] with care in premature infants or infants under } 2 \\
\text { months of age." } 13 \\
\text { - For infants born at }<28 \text { weeks gestation, especially } \leq 7 \text { days of age, NICUs } \\
\text { may consider use of aqueous } 2 \% \text { CHG for skin antisepsis. }\end{array}$ \\
\hline 2 & $\begin{array}{l}\text { How often should CVC dressings be changed in NICU } \\
\text { infants? }\end{array}$ & $\begin{array}{l}\text { - To reduce skin barrier breakdown and the risk for dislodgement of the CVC, } \\
\text { CVC dressings should be changed only if soiled, damp, or loose, regardless of } \\
\text { gestational age (and not according to a specific interval of time, eg, every } 7 \\
\text { days). } \\
\text { - The integrity of the CVC dressing should be inspected by designated HCP at } \\
\text { least daily. }\end{array}$ \\
\hline 3 & $\begin{array}{l}\text { In which NICU patients should CHG-impregnated } \\
\text { sponges or other CHG-impregnated dressings be used? }\end{array}$ & $\begin{array}{l}\text { - CHG-impregnated dressings are associated with an increased risk of contact } \\
\text { dermatitis in NICU infants. Benefits have not been demonstrated in NICU } \\
\text { infants and these products are not recommended by the authors. }{ }^{25} \\
\text { - If other interventions have failed to reduce CLABSI in an infant in the NICU, } \\
\text { or if there is an increase in the NICU's baseline CLABSI rates, CHG- } \\
\text { impregnated dressings may be considered in infants } \geq 28 \text { weeks gestation } \\
\text { and } \geq 7 \text { days of age. }\end{array}$ \\
\hline 4 & Should alcohol disinfectant caps be used in the NICU? & $\begin{array}{l}\text { - NICUs may consider use of disinfectant caps as an additional intervention to } \\
\text { reduce CLABSI rates when other interventions have failed. }\end{array}$ \\
\hline 5 & $\begin{array}{l}\text { In which NICU patients are the benefits of CHG bathing } \\
\text { likely to outweigh the risks? }\end{array}$ & $\begin{array}{l}\text { - Routine CHG bathing is not recommended for all NICU infants. } \\
\text { - In NICUs that have high CLABSI rates (see Question } 10 \text { ), despite } \\
\text { implementation of other evidence-based strategies, CHG bathing may be } \\
\text { used in the NICU for infants with CVCs. The optimal frequency of CHG- } \\
\text { bathing has not been established and depends on chronological age and } \\
\text { gestational age: } \\
\text { o CHG bathing in term infants ( } \geq 37 \text { weeks): may be performed from birth. } \\
\text { o CHG bathing in preterm infants ( }<37 \text { weeks gestation) may be } \\
\text { considered beginning at } 4 \text { weeks of chronological age, recognizing the } \\
\text { potential for skin irritation and systemic absorption (the latter being of } \\
\text { unknown clinical significance). } \\
\text { o CHG bathing in preterm infants ( }<37 \text { weeks gestation) and }<4 \text { weeks of } \\
\text { age is not recommended due to potential adverse local and systemic } \\
\text { effects. In these infants, an alternative approach of bathing with sterile } \\
\text { water with or without mild soap may help decrease bacterial counts on } \\
\text { skin. } \\
\text { - When CHG bathing is utilized, NICUs should ensure careful surveillance for } \\
\text { local and systemic adverse effects, including allergic reactions. }\end{array}$ \\
\hline 6 & $\begin{array}{l}\text { What are practical strategies for minimizing central-line } \\
\text { entry in NICU patients? }\end{array}$ & $\begin{array}{l}\text { - NICUs should perform laboratory and diagnostic stewardship (ie, } \\
\text { consolidation of necessary tests and elimination of those not clinically } \\
\text { relevant). } \\
\text { - HCP should avoid using the CVC to obtain routine blood tests. } \\
\text { - Although not a universal recommendation, NICUs may consider the use of } \\
\text { closed blood sampling systems. } \\
\text { - The utility of obtaining blood cultures through an indwelling CVC remains an } \\
\text { unresolved issue. }\end{array}$ \\
\hline 7 & $\begin{array}{l}\text { When and how should prophylactic antimicrobial lock } \\
\text { therapy be implemented in NICU patients? }\end{array}$ & $\begin{array}{l}\text { - Prophylactic antimicrobial lock therapy as a universal prevention measure is } \\
\text { not recommended. } \\
\text { - Antimicrobial locks may be considered as an additional intervention in NICU } \\
\text { infants with recurrent CLABSIs. }\end{array}$ \\
\hline 8 & $\begin{array}{l}\text { Should prophylactic antimicrobials be administered to a } \\
\text { NICU patient at the time of PICC removal to reduce the } \\
\text { incidence of CLABSI or culture-positive sepsis? }\end{array}$ & $\begin{array}{l}\text { - Prophylactic antimicrobials are not recommended at the time of PICC } \\
\text { removal. }\end{array}$ \\
\hline 9 & $\begin{array}{l}\text { What are practical considerations for the } \\
\text { implementation of a neonatal vascular access team } \\
\text { (VAT)? }\end{array}$ & $\begin{array}{l}\text { - NICUs should consider use of a VAT. Such teams have demonstrated } \\
\text { effectiveness in reducing catheter-related complications and are cost- } \\
\text { effective. }{ }^{22,81-83} \\
\text { - VAT proceduralists should receive education and clinical training, and upon } \\
\text { completion, demonstrate knowledge and proficiency in PICC insertion, care, } \\
\text { and removal, and a commitment to the team-based approach. } \\
\text { - VAT proceduralists should successfully insert a predefined number of PICCs } \\
\text { as defined by the local facility's delineation of privileges. } \\
\text { - The team should monitor relevant quality measures (see Table } 7 \text { ). }\end{array}$ \\
\hline
\end{tabular}


Table 2. (Continued)

\begin{tabular}{|c|c|c|}
\hline$\#$ & Question & Answer \\
\hline 10 & $\begin{array}{l}\text { What threshold should prompt a NICU to consider } \\
\text { implementing additional preventive measures? }\end{array}$ & $\begin{array}{l}\text { - Zero CLABSIs is the aspirational and potentially achievable goal. } \\
\text { - Although there is no nationally endorsed threshold above which additional } \\
\text { CLABSI prevention measures should be implemented, a variety of } \\
\text { quantitative or qualitative metrics may be utilized to identify CLABSI } \\
\text { prevention success over time and determine when additional intervention is } \\
\text { necessary. } \\
\text { - A decision to identify a threshold for action in an individual NICU should } \\
\text { assess a variety of factors including: } \\
\text { o An SIR or rate of CLABSI that is above goal or increasing despite the } \\
\text { consistent implementation of current organizational interventions } \\
\text { o Local interest in setting a specific lower target with input from Infection } \\
\text { Prevention and Control (infection preventionists, healthcare } \\
\text { epidemiologist) } \\
\text { o Patient mix and clinical acuity, which may predict general likelihood of } \\
\text { CLABSI } \\
\text { o Resource and personnel capacity for initiation and/or maintenance of } \\
\text { specific interventions and practice processes. } \\
\text { - Any quantitative or qualitative metric that is defined should be developed } \\
\text { and accepted by all stakeholders. }\end{array}$ \\
\hline 11 & $\begin{array}{l}\text { What preventive bundle elements, above and beyond } \\
\text { those recommended by CDC, could be considered by a } \\
\text { NICU experiencing ongoing CLABSIs? }\end{array}$ & $\begin{array}{l}\text { - Additional practices that lack robust evidence may be effective. NICUs may } \\
\text { consider many different products, technologies, and processes, some of } \\
\text { which are described below. } \\
\text { - Implementation of an expanded NICU central-line care bundle should take } \\
\text { into account the risks and benefits of additional measures, as well as the } \\
\text { needs, resources, and local expertise at individual institutions. }\end{array}$ \\
\hline
\end{tabular}

served as volunteers. At their respective institutions, the authors are directly involved or provide an advisory role in the development of policies pertaining to pediatric and/or neonatal infection prevention in the NICU.

The NICU Advisory Panel (see the Acknowledgments), a collaborative group of pediatric and pathogen-specific experts convened by SHEA, provided oversight and review of the draft document.

\section{Practical approaches: Questions and Answers}

Questions and recommendations are listed in Table 2.

Question 1: Which NICU patients are likely to benefit from use of chlorhexidine (CHG) skin antisepsis for CVC insertion and maintenance?

\section{Answer 1:}

- Skin antisepsis should occur for all infants in the NICU and optimally should be performed with a CHG-containing product.

- For infants $\geq 8$ weeks of age or older, $2 \%$ CHG in $70 \%$ alcohol should be used.

- For infants $<8$ weeks of age, the authors' clinical experience shows that a CHG-containing product may be used safely. Additionally, the US Food and Drug Administration (FDA) has stated that CHG may be "[used] with care in premature infants or infants under 2 months of age."13

- For infants born at $<28$ weeks gestation, especially $\leq 7$ days of age, NICUs may consider use of aqueous $2 \%$ CHG for skin antisepsis.

A variety of antiseptics, containing differing amounts of $\mathrm{CHG}$, with and without alcohol (aqueous CHG), are available. The use of a CHG-containing skin antiseptic, in combination with alcohol, for CVC insertion and maintenance is preferred, based on its efficacy in reducing CLABSI in populations outside the NICU. In the $\mathrm{NICU}$, the optimal concentration of CHG-containing agent has not been determined. Although the FDA has stated that CHG may be "[used] with care in premature infants or infants under 2 months of age,"13 the authors' clinical experience shows that it may be used safely. Figure 1, from the Centre Hospitalier Universitaire (CHU) Sainte-Justine Hospital in Montreal, Canada details how one hospital has operationalized options for antisepsis for various procedures commonly performed in the NICU setting. Although more detailed than the recommendations provided in this document, it could serve as a useful model for NICUs seeking to implement the use of CHG. Infants ( $\geq 8$ weeks of age) may benefit from a higher CHG concentration (ie, $2 \%$ ) (Fig. 1). ${ }^{14}$ For CVC insertion, some centers use $2 \%$ aqueous rather than alcohol-based CHG in extremely preterm infants ( $<28$ weeks gestation), but recommend that, once dried, $\mathrm{CHG}$ should be rinsed off the skin with sterile water to prevent burns. However, Garland et $\mathrm{al}^{15}$ showed that the application of $2 \% \mathrm{CHG}$ in $70 \%$ isopropyl alcohol for skin antisepsis before CVC placement and with each weekly dressing change in infants weighing $\geq 1500$ grams and $\geq 7$ days of age was not associated with dermatitis although cutaneous absorption of CHG occurred in $15 \%$ of infants. ${ }^{15}$

As an alternative to alcohol-based CHG solutions that may potentiate skin irritation and cutaneous $\mathrm{CHG}$ absorption, some NICUs use $1 \%$ or $2 \%$ aqueous CHG for skin antisepsis. In a randomized, blinded, non-inferiority trial of 308 infants who were 2642 weeks gestation, the use of $1 \%$ aqueous CHG for skin antisepsis was comparable to a $2 \%$ aqueous $\mathrm{CHG}$ solution when assessed by the proportion of negative skin swab cultures after skin antisepsis. ${ }^{14}$ Overall, $93 \%$ of swabs were sterile in the $1 \% \mathrm{CHG}$ group compared with $95.6 \%$ in the $2 \%$ CHG group (risk difference, $-2.7 \%$; $95 \% \mathrm{CI},-6.2$ to $+0.8 \%)$. The lower bound of the $95 \% \mathrm{CI}$ crossed the prespecified absolute non-inferiority limit of 5\%. Mild dermatitis was identified in $2.3 \%$ of infants in each group, with the worst being transient slightly pink discoloration of the skin without edema. Percutaneous absorption of chlorhexidine occurred in all 59 sampled infants but did not differ by the concentration of the aqueous preparation with the median CHG concentration at 


\begin{tabular}{|c|c|c|c|}
\hline & \multicolumn{3}{|c|}{ All Antiseptics } \\
\hline Minimum contact time & \multicolumn{3}{|c|}{$>30$ seconds } \\
\hline Drying time & \multicolumn{3}{|c|}{ Let all dry completely } \\
\hline & \multicolumn{3}{|c|}{ All Infants } \\
\hline Vial cap & \multicolumn{3}{|c|}{ Alcohol 70\% swab } \\
\hline Injections IM, SC, ID, etc. & \multicolumn{3}{|c|}{ Alcohol $70 \%$ swab } \\
\hline $\begin{array}{l}\text { Injection site, needleless } \\
\text { connectors, } \\
\text { "scrub the hub" }\end{array}$ & \multicolumn{3}{|c|}{ Alcohol $70 \%$ swab } \\
\hline Blood procurement & \multicolumn{3}{|c|}{ Alcohol 70\% swab } \\
\hline Age and weight & $\begin{array}{l}-\quad<28 \text { weeks } \\
\text { gestation OR } \\
\quad<1000 \mathrm{~g} \\
\text { AND } \\
\text { - } \quad 4 \text { weeks of life }\end{array}$ & $\begin{array}{c}\text { Everyone else } \\
\text { not included in } \\
\text { columns to left or } \\
\text { right }\end{array}$ & $\begin{array}{l}\text { Term infant } \\
\text { AND } \\
\text { - } \geq 4 \text { weeks of life }\end{array}$ \\
\hline Blood cultures & CHG $2 \%$ aqueous & $\begin{array}{l}\text { CHG } 0.5 \%+ \\
\text { alcohol } 70 \% \text { swab }\end{array}$ & $\begin{array}{l}\text { CHG } 2 \%+ \\
\text { alcohol } 70 \% \text { swab }\end{array}$ \\
\hline Arterial draws & CHG $2 \%$ aqueous & $\begin{array}{l}\text { CHG } 0.5 \%+ \\
\text { alcohol } 70 \% \text { swab }\end{array}$ & $\begin{array}{l}\text { CHG 2\% + } \\
\text { alcohol 70\% swab }\end{array}$ \\
\hline Peripheral IV insertion & CHG $2 \%$ aqueous & $\begin{array}{l}\text { CHG 0.5\%+ } \\
\text { alcohol 70\% swab }\end{array}$ & $\begin{array}{l}\text { CHG } 2 \%+ \\
\text { alcohol } 70 \% \text { swab }\end{array}$ \\
\hline $\begin{array}{l}\text { CVC insertion (includes } \\
\text { UAC/UVC, PICC) }\end{array}$ & $\begin{array}{l}\text { CHG } 2 \% \text { aqueous } \\
\text { swabstick }\end{array}$ & \multicolumn{2}{|c|}{ CHG $0.5 \%+$ alcohol $70 \%$ swabstick } \\
\hline CVC insertion site & $\begin{array}{l}\text { CHG } 2 \% \text { aqueous } \\
\text { swabstick }\end{array}$ & \multicolumn{2}{|c|}{ CHG $0.5 \%+$ alcohol $70 \%$ swabstick } \\
\hline
\end{tabular}

*The recommendations in this table are presented as an example of how one hospital implemented CHG use in a NICU and are more detailed than the recommendations presented in the text.
Fig. 1. Use of antiseptics in the NICU at CHU SainteJustine Hospital in Montreal, Canada.
24 hours being $19.6 \mathrm{ng} / \mathrm{mL}$ and $12.6 \mathrm{ng} / \mathrm{mL}$ in the $1 \%$ and $2 \%$ aqueous CHG group, respectively. ${ }^{14}$ Therefore, use of the lower CHG concentration does not offer any substantial safety advantage.

CHG skin antisepsis is commonly used in many NICUs. In 2016, a survey of 58 academic NICUs in the United States found that CHG was used by $86 \%$ of centers, mostly for skin antisepsis at the time of CVC insertion, CVC dressing changes, CVC maintenance, and peripheral intravenous catheter insertion. In NICUs where $\mathrm{CHG}$ was restricted by age or weight, the most common requirements for $\mathrm{CHG}$ use were gestational age $>28$ weeks and weight $>1000$ grams. $^{16}$

CHG-based skin antisepsis has demonstrated superiority compared to povidone-iodine in settings outside the NICU. ${ }^{17}$ Limited data from clinical trials in the NICU have failed to demonstrate superiority of either product from a safety and efficacy standpoint, although the use of povidone-iodine was associated with an increased risk of high thyroid stimulating hormone level requiring treatment. ${ }^{15,18}$ Recent guidelines from CDC for the prevention of CLABSIs in NICU patients advise to "consider the use of alcoholcontaining chlorhexidine for skin antisepsis to prevent centralline-associated bloodstream infection (CLABSI) in neonatal intensive care unit (NICU) patients in whom the benefits are judged to outweigh the potential risks." "The consensus of the authors is that CHG-based skin antisepsis and not an iodine-based product is optimal for all infants regardless of gestational age and birth weight.

Frequent inspection of the skin site where CHG has been applied is important to detect and manage cutaneous adverse effects including chemical burns. ${ }^{19}$ To decrease their occurrence, only the minimum amount of CHG-containing solution should be used, with removal of any excess solution, as well as any soaked materials or drapes, from the skin. Parents should be informed of the potential for CHG to cause skin irritation at the time consent for CVC placement is obtained. ${ }^{20}$ When severe dermatitis or chemical burns occur, temporary use of povidone-iodine or a lower concentration of aqueous CHG may be needed until the skin injury is healed. Consultation with the NICU wound team or other specialists such as burn and plastic surgeons may be necessary.

\section{Question 2: How often should CVC dressings be changed in} NICU infants?

\section{Answer 2:}

- To reduce skin barrier breakdown and the risk for dislodgement of the CVC, CVC dressings should be changed only if soiled, damp, or loose, regardless of gestational age (and not according to a specific interval of time, eg, every 7 days). 
Table 3. Adapted CDC Checklist for Prevention of CLABSI ${ }^{\star 8,17}$

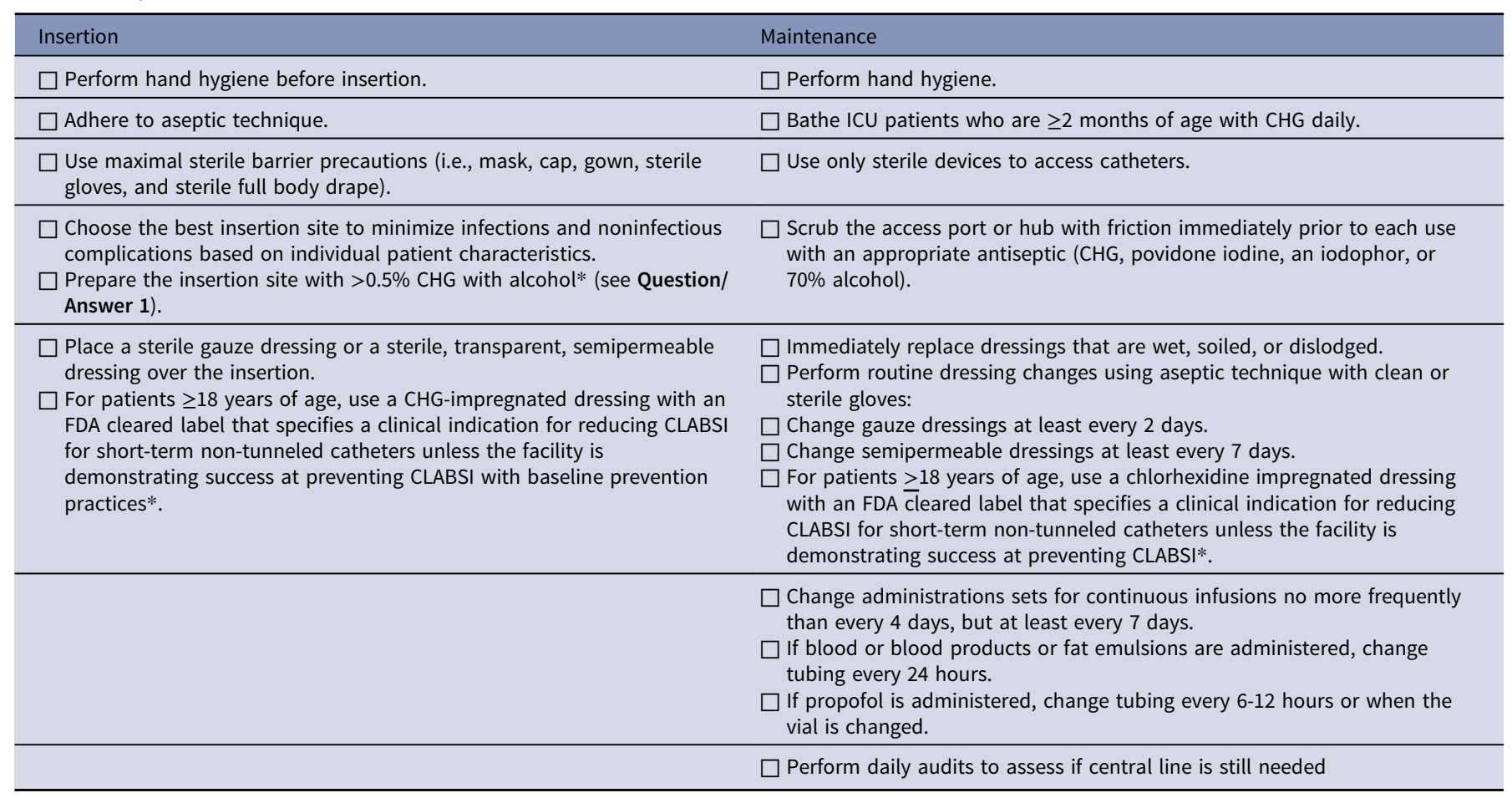

*This is the complete CDC checklist. Some recommendations are different from those in this paper or are not pertinent because they are specific to older patients. The recommendations in this paper reflect the nuances of care in the NICU.

- The integrity of the CVC dressing should be inspected by designated HCP at least daily.

Transparent CVC dressings have been recommended to be changed every 7 days, and more frequently if soiled, damp, or loose. ${ }^{21}$ However, it also is likely that in extremely preterm infants in particular ( $<28$ weeks gestation), each dressing removal may result in skin barrier breakdown leading to an increased risk of CLABSI. Some NICUs will only change a transparent dressing if it is soiled, damp, or loose, and this is the authors' consensus recommendation for all NICU patients regardless of gestational or chronologic age or weight. Although the authors acknowledge that this is different than the CDC recommendation (Table 3), deferring changing dressings of NICU patients if they are intact has been recommended by other experts. ${ }^{17,22,23}$ Daily inspection of the dressing's integrity, preferably by a dedicated team or trained bedside nurse, is recommended.

Very limited data suggest that use of cyanoacrylate glue at the CVC insertion site may decrease bleeding and thus increase the time between dressing changes in extremely preterm infants. In one NICU the addition of cyanoacrylate glue to the insertion bundle for percutaneously placed CVCs significantly reduced accidental catheter dislodgement and anecdotally reduced bleeding at the insertion site. ${ }^{24}$

Question 3: In which NICU patients should CHG-impregnated sponges or other CHG-impregnated dressings be used?

\section{Answer 3:}

- CHG-impregnated dressings are associated with an increased risk of contact dermatitis in NICU infants. Benefits have not been demonstrated in NICU infants, and these products are not recommended by the authors. ${ }^{25}$

- If other interventions have failed to reduce CLABSI in an infant in the NICU, or if there is an increase in the NICU's baseline CLABSI rates, $\mathrm{CHG}$-impregnated dressings may be considered in infants $\geq 28$ weeks gestation and $\geq 7$ days of age.

Several types of dressings incorporate chlorhexidine, including CHG-impregnated sponges, transparent dressings, and films. A CHG-impregnated sponge, also called a patch or disk, is a device composed of sterile polyurethane foam impregnated with CHG. It is intended to be applied at the insertion site of a central line before a sterile, transparent dressing is placed. This device is designed to provide continuous protection from skin recolonization by slowly releasing CHG while also absorbing and drawing fluids away from the site. ${ }^{26}$ The use of CHG-impregnated sponges (eg, Biopatch Protective Disk with CHG, Ethicon, Raritan, NJ) has been shown to reduce CLABSIs in adults, but the benefits are less clear in pediatric patients. ${ }^{27}$ The National Health Service (NHS UK) recommends that if used, CHG-impregnated sponges should be restricted to infants $\geq 28$ weeks gestation and $\geq 7$ days of age and that pressure over the sponge be avoided to prevent skin necrosis. ${ }^{28}$ Adverse skin reactions, including dermatitis and cellulitis at the insertion site, may occur and may not be visible under the sponge, and this may be a deterrent to their use in some infants.

Dressings impregnated with antiseptics or antibiotics (ie, antimicrobial dressings) have also been studied in NICU infants. ${ }^{8,29} \mathrm{~A}$ Cochrane review evaluated the effectiveness and safety of antimicrobial dressings used at the time of CVC insertion in reducing CLABSIs in the NICU. Compared to polyurethane dressing/ 
povidone-iodine cleansing, CHG sponges/alcohol cleansing reduced catheter colonization (risk ratio [RR], 0.62; 95\% CI, 0.45-0.86) but did not change the important outcomes of bloodstream infection (BSI; RR, 1.18; 95\% CI, 0.53-2.65) or sepsis (RR, 1.06; 95\% CI, 0.75-1.52). ${ }^{29}$ In addition, the use of CHG-impregnated dressings was associated with contact dermatitis in preterm infants (RR, 43.06; 95\% CI, 2.61-710.44). ${ }^{29}$ The use of a silver-alginate patch appeared safe, but there was insufficient evidence of benefit.

The CDC Checklist for the Prevention of CLABSI does not recommend the use of CHG-impregnated dressings (including sponges) to protect the sites of short-term, nontunneled CVCs for premature infants due to the risk of serious adverse skin reactions. While recent guidance recommends the use of chlorhexidine-containing dressings for patients $>2$ months of age with CVCs, use of dressings in younger infants, particularly in pre-term or very low birthweight infants, remains an unresolved issue. $^{17}$

Some NICUs utilize CHG dressings for selected infants. Of 50 neonatology training program directors in the United States who responded to a 2014 survey, 10 (20\%) reported using impregnated dressings or disks (the survey did not differentiate between the products).${ }^{16}$ A survey of SHEA Pediatric Leadership Council members in April 2014 revealed that 5 (19\%) of 26 NICUs used a "CHG dressing" on infants with surgically placed CVCs but the criteria for use were variable and included infants who were $>28$ weeks gestation and weighing $>1,000$ grams, $\geq 34$ weeks corrected age, or $>2$ months chronologic age. Only 3 (11\%) of 27 NICUs used CHG dressings on similar infants with peripherally inserted central catheters (PICCs, also called percutaneously inserted CVCs). ${ }^{30}$ The survey did not differentiate between sponges and impregnated dressings.

\section{Question 4: Should alcohol disinfectant caps be used in the NICU?}

\section{Answer 4:}

- NICUs may consider use of disinfectant caps as an additional intervention to reduce CLABSI rates when other interventions have failed.

Access of pathogenic organisms to the bloodstream via a CVC is prevented in part by careful disinfection of the catheter hub. The manual "scrub-the-hub" process is time-consuming; thus, compliance by HCP may be suboptimal. Disinfectant caps containing 70\% isopropyl alcohol placed over intravenous needleless connectors act as antiseptic barriers by passive disinfection, decreasing hub colonization. ${ }^{31}$ Two in vitro studies found leakage of alcohol through the hub membrane, ${ }^{32,33}$ but the potential clinical significance of this leakage is unknown. Adverse effects resulting from alcohol leakage in a clinical setting have not been identified. In vitro, alcohol leakage can vary by cap manufacturer and may be reduced by allowing the hub membrane to dry for 30 seconds prior to an infusion and limiting the number of days that the cap remains in place (ie, $<7$ days).

In pediatric patients, disinfectant caps have been used in many hospitals, usually as part of a bundle, with subsequent reduction in CLABSIs. In 2019, the National Institute of Health and Care Excellence (NICE) cited disinfectant caps as a potential intervention to reduce CLABSIs, but due to insufficient evidence, further research to assess their clinical benefit was recommended. ${ }^{34} \mathrm{~A}$ systematic review that included 9 studies comparing the effects of disinfectant caps (Curos ${ }^{\mathrm{TM}}$ and SwabCap ${ }^{\mathrm{TM}}$ ) with manual disinfection in multiple US and UK hospital settings (including 1 pediatric hospital) found that disinfectant caps effectively reduced CLABSIs (incidence rate ratio [IRR], 0.59; 95\% CI, $0.45-0.77 ; P<.001)$ and were cost-saving. ${ }^{35}, 36$, In a prospective, single-center, pre- and post-observational study conducted in pediatric intensive care units (PICUs) and NICUs, CLABSI rates decreased by $22 \%$ with the use of disinfectant caps compared to the manual scrub-the-hub method, but the difference was not statistically significant (95\% CI, 34\%-55\%; $P=.368) .{ }^{36}$ Among ambulatory pediatric oncologic patients, a randomized controlled trial evaluating disinfectant caps did not demonstrate a significant reduction in CLABSI incidence. ${ }^{37}$

Despite the lack of supportive evidence in pediatrics, many NICUs utilize disinfectant caps without reporting clinically significant adverse effects. A survey conducted by the SHEA Pediatric Leadership Council in April 2014 showed that 9 (33\%) of 27 participating NICUs used ethanol or alcohol caps on all hubs or ports of the intravenous administration set in all NICU patients. ${ }^{30}$

Question 5: In which NICU patients are the benefits of CHG bathing likely to outweigh the risks?

\section{Answer 5:}

- Routine CHG bathing is not recommended for all NICU infants.

- In NICUs that have high CLABSI rates (see Question 10), despite implementation of other evidence-based strategies, CHG bathing may be used in the NICU for infants with CVCs. The optimal frequency of CHG-bathing has not been established and depends on chronological age and gestational age:

o CHG bathing in term infants ( $\geq 37$ weeks): may be performed from birth.

o CHG bathing in preterm infants $<37$ weeks gestation may be considered beginning at 4 weeks of chronological age, recognizing the potential for skin irritation and systemic absorption (the latter being of unknown clinical significance).

o CHG bathing in preterm infants ( $<37$ weeks gestation) and $<4$ weeks of age is not recommended due to potential adverse local and systemic effects. In these infants, an alternative approach of bathing with sterile water with or without mild soap may help decrease bacterial counts on skin.

- When CHG bathing is utilized, NICUs should ensure careful surveillance for local and systemic adverse effects, including allergic reactions.

The use of CHG for skin antisepsis and the use of CHG for bathing are distinct interventions with unique sets of benefits and risks in NICU infants ${ }^{38}$. Daily bathing of ICU patients $\geq 8$ weeks (ie, $\geq 2$ months) is now considered to be standard infection prevention practice $^{17}$ including patients in the NICU. With the exception of children with cancer or those undergoing hematopoietic stem cell transplantation, daily CHG bathing of children in the PICU who were $\geq 2$ months of age ( 8 weeks) resulted in decreased bacteremia and CLABSIs. ${ }^{39}$ Recommendations for bathing younger infants, especially preterm infants, is more nuanced. Bathing infants with cloths infused with $\mathrm{CHG}$ decreases bacterial colony counts on skin transiently. ${ }^{40,41}$ Nonrandomized trials in NICU patients suggest a decrease in CLABSI rates in CHG-bathed neonates in the absence of observed adverse events. ${ }^{42,43}$ However, safety concerns persist, especially in very preterm infants whose poor skin integrity may predispose them to contact dermatitis, chemical burns, and systemic absorption. ${ }^{44}$ An additional concern comes from studies 
in pediatric and adult patients that have noted higher prevalence of reduced CHG susceptibility in organisms that cause CLABSIs in units that perform daily CHG bathing of patients. ${ }^{45}$ In adults, the potential development of cross resistance to other cell-envelope agents such as daptomycin and colistin has raised further concerns. These phenomena have not been evaluated in NICU patients.

For these reasons, CHG bathing has not been used routinely in extremely preterm ( $<28$ weeks gestation) infants with birth weights of $\leq 1,000$ grams who are $<4$ weeks of age, and alternate bathing methods with sterile water and/or mild soap are advocated. However, based on decreases in CLABSI rates in CHG-bathed neonates as noted above, CHG bathing may be considered in more mature preterm and term infants between 4 and 8 weeks of age if CLABSI rates remain high despite implementation of other evidence-based interventions.

\section{Question 6: What are practical strategies for minimizing cen- tral-line entry in NICU patients?}

\section{Answer 6:}

- NICUs should perform laboratory and diagnostic stewardship (ie, consolidation of necessary tests and elimination of those not clinically relevant).

- HCP should avoid using the CVC to obtain routine blood tests.

- Although not a universal recommendation, NICUs may consider the use of closed blood sampling systems.

- The utility of obtaining blood cultures through an indwelling CVC remains an unresolved issue.

Infants in the NICU require frequent blood draws for clinical monitoring. CDC guidelines for CLABSI prevention in NICU patients recommend minimizing the number of times central-line hubs are accessed, as well as minimizing blood sampling through central lines, even though high-quality data are lacking. ${ }^{9,46}$ Only 1 study among infants in the NICU reported an increased risk of CLABSI from procedures involving catheter manipulation such as disinfection of the catheter hub following disconnection of the CVC (OR, 1.2; 95\% CI, 1.1-1.3) and blood sampling other than for blood gases (OR, 1.4; 95\% CI, 1.1-1.8). ${ }^{47}$ The authors reported a cumulative dose-effect of the number of blood samples obtained from the CVC with an odds ratio (OR) of 1.04 for 1-7 blood samples (95\% CI, $0.33-3.27 ; \mathrm{P}=0.95)$ to $8.4(95 \% \mathrm{CI}, 0-67.1 ; \mathrm{P}=0.036)$ for $>14$ blood samples. Obtaining blood samples by other methods may also create risk. In an observational case-control study, there was an increased risk of CLABSI among NICU infants who had at least 3 capillary blood draws by heel punctures within 48 hours before CLABSI onset (OR, 5.36; 95\% CI, 2.37-12.15). ${ }^{48}$ This retrospective study could not confirm causality, but it is plausible that multiple skin breaks contributed to the development of bacteremia.

The first steps in decreasing the number of central-line system entries are (1) not using CVCs for routine blood draws and (2) performing laboratory and diagnostic stewardship to minimize tests that are not clinically relevant. Reducing laboratory testing is an achievable goal. After implementing a multifaceted quality improvement project that included guideline development, dashboard creation and distribution, electronic medical record optimization, and expansion of noninvasive and point-of-care testing, one NICU achieved a $26.8 \%$ decrease in routine laboratory testing per 1,000 patient days over a 24 -month period. ${ }^{49}$

The utility of obtaining blood cultures through an indwelling CVC remains controversial. In general, catheter-drawn blood cultures have higher rates of contamination (ie, false positives), ${ }^{50}$ and some expert guidance recommends peripheral venipuncture as the preferred method for obtaining blood cultures. ${ }^{51}$ The Bright Star Collaborative is a multicenter quality improvement collaborative that includes children's hospitals in 17 states across the United States. ${ }^{52}$ The mission of the group is to reduce bacterial culture overuse in critically ill children by implementing diagnostic stewardship interventions. Consensus recommendations from the group for PICU patients advise against obtaining blood cultures from every lumen of a CVC or from a peripheral intravenous catheter. The group did not reach consensus regarding the utility of a blood culture drawn from a CVC, since a positive culture cannot differentiate between catheter colonization or BSI. ${ }^{53} \mathrm{NICU}$-specific recommendations do not exist but the issues are likely to be similar.

The clinician must weigh practical considerations when deciding how to obtain blood cultures in a NICU patient. The NHSN surveillance definitions for CLABSI require 2 positive blood cultures, taken at different sites or at different times, when potential commensal bacteria (eg, coagulase-negative staphylococci) are detected to diagnose a true device-associated infection. It may be difficult to obtain 2 separate samples by peripheral venipuncture in NICU infants. A CVC sample may be paired with a peripherally obtained sample to help differentiate between catheter colonization and a true BSI, especially when a commensal organism is isolated. A CVC culture is considered to have higher sensitivity compared to peripheral specimens, at the cost of lower specificity. ${ }^{54}$ Finally, HCP also may opt to draw a blood culture from a CVC to minimize painful procedures. A recent study conducted at a level IV NICU compared concurrently drawn peripheral and catheter blood cultures and found that most blood cultures were positive with the same organism from both sites, although a small but important minority of episodes (12\%) grew virulent pathogens from either culture site alone. ${ }^{50}$ The authors concluded that while dual-site blood-culture practices may be useful, the gain in sensitivity of bacteremia detection should be weighed against additive contamination risk. Even when HCP want to obtain a blood culture from a CVC, it may not be feasible. Catheters with very small lumens may collapse when suction is applied during the blood draw.

Adopting the Bright Star Consensus Recommendations for PICU patients may reduce the total number of blood cultures ordered, as well as the number of samples obtained through the catheter. Before ordering a blood culture, HCP should review the patient's clinical data, including previous cultures, and perform a physical examination, and they should discuss the patient's status with the bedside nurse. If a blood culture needs to be drawn from the CVC, then additional blood draws can be performed at the same time or scheduled with other required laboratory tests to decrease system entry. ${ }^{53}$ Because bacteremia occurs before the onset of fever, once the fever has occurred, the timing of the blood culture is not as critical except in situations when obtaining a blood culture before a change in antimicrobial therapy informs antimicrobial stewardship efforts.

Previous studies have shown that closed infusion systems are associated with a decrease in overall CLABSI rates compared to open-infusion systems. Other studies have proposed that closed blood-sampling systems, such as the venous arterial blood management and protection $\left(\mathrm{VAMP}^{\mathrm{TM}}\right)$ and $\mathrm{KidsKit}^{\mathrm{TM}}$ systems, decrease system entry, blood waste, and microbial contamination. ${ }^{55-57}$ A pediatric study evaluated both systems and compared implementation of the KidsKit system to the conventional 3-way stopcock methods used on umbilical arterial catheters in the PICU and NICU. The authors found a decrease in CLABSIs below the national benchmark. ${ }^{57}$ NICUs may consider use of a closed 
Table 4. Considerations for Use of Lock Therapies in NICU Patients ${ }^{96}$

\begin{tabular}{|c|c|}
\hline \multicolumn{2}{|c|}{ Prophylactic Antimicrobial Lock Therapy } \\
\hline Optimal Procedures: & $\begin{array}{l}\text { - Pharmacy-dispensed volume-specific syringes for each lumen } \\
\text { - Minimum dwell time of } 4 \text { hours, without disruption, while all lumens are locked } \\
\text { - Changing all line lock solutions inserted into ports every } 24 \text { hours } \\
\text { - Routine administration of a thrombolytic drug other than saline or heparin to maintain } \\
\text { catheter patency (e.g., alteplase). Each lumen of the catheter should be easy to flush and aspirate } \\
\text { - VAT evaluation and intervention if unable to withdraw antimicrobial lock from any lumen }\end{array}$ \\
\hline Do not use for: & $\begin{array}{l}\text { - Infants with allergy to any component of antimicrobial lock therapy } \\
\text { - } 2 \text { French or smaller PICCs, umbilical arterial and venous catheters, arterial lines, midline catheters, } \\
\text { and peripheral intravenous catheters } \\
\text { - Infants who are receiving continuous infusions that require a dedicated lumen line (e.g., amiodarone, } \\
\text { heparin, narcotics, pressors, and TPN) } \\
\text { - Obtaining antimicrobial levels }\end{array}$ \\
\hline Do not use if: & $\begin{array}{l}\text { - Lock is incompatible with catheter being used } \\
\text { - Patency of line cannot be assessed } \\
\text { - Logistical challenges of rotating lumens when multiple lumens and/or catheters require antimicrobial } \\
\text { lock therapy make use ineffective }\end{array}$ \\
\hline \multicolumn{2}{|c|}{ Considerations for Ethanol Lock Therapy } \\
\hline \multicolumn{2}{|c|}{ Ethanol lock therapy has very limited use in the $\mathrm{NICU}^{65,67,70}$} \\
\hline Do not use in: & $\begin{array}{l}\text { - A non-silicone central catheter } \\
\text { - A peripherally inserted central catheter }\end{array}$ \\
\hline Do not use if: & $\begin{array}{l}\text { - The catheter has more than } 1 \text { lumen } \\
\text { - The infant is less than } 6 \text { months of age } \\
\text { - The infant weighs less than } 5 \mathrm{~kg} \\
\text { - The infant is receiving continuous infusions. Ethanol may precipitate if in contact with TPN and cause catheter occlusion } \\
\text { - Inability to maintain the lock for a minimum of } 4 \text { hours (optimal dwell time) }\end{array}$ \\
\hline
\end{tabular}

blood-sampling system as a potential intervention when CLABSI rates remain elevated despite high rates of compliance with insertion and maintenance bundles.

\section{Question 7: When and how should prophylactic antimicrobial lock therapy be implemented in NICU patients?}

\section{Answer 7:}

- Prophylactic antimicrobial lock therapy as a universal prevention measure is not recommended.

- Antimicrobial locks may be considered as an additional intervention in NICU infants with recurrent CLABSIs.

Antimicrobial locks are solutions used for prophylactic or adjunctive treatment of CLABSI when the catheter cannot be removed in the setting of bacteremia. They contain a solution of highly concentrated antimicrobial agent in combination with an anticoagulant that is inserted into the lumen of a CVC and removed after a specified period (dwell time). Three randomized controlled trials in NICU infants demonstrated that use of prophylactic antimicrobial lock therapy decreased CLABSIs in NICUs with high baseline CLABSI rates. ${ }^{58-60}$ These studies, however, were conducted before routine implementation of insertion and maintenance bundles, which have reduced NICU CLABSI rates substantially. We do not, therefore, recommend prophylactic antimicrobial lock therapy as a universal prevention measure, although it may be considered in individual infants who experience recurrent CLABSIs. The authors recommend collaboration with a pediatric infectious diseases specialist and the NICU vascular access team (VAT) before implementation of lock therapy.

NICUs will need to consider practical implementation challenges, including that some catheters are not suitable for antimicrobial locks and that the optimal minimum dwell time for lock therapy is 4 hours (Table 4 ).

There is no single preferred antimicrobial lock preparation. Several concentrations of antimicrobial agents and ethanol have been studied in combination with heparin and other anticoagulants (Table 5). When used, antimicrobial locks should have activity against common CLABSI pathogens, the ability to penetrate biofilms, compatibility with anticoagulants such as heparin or an alternative ion chelator such as citrate, and prolonged stability. ${ }^{61}$ In addition, they should have low risk of toxicity and low potential for inducing antimicrobial resistance. Ampicillin and other $\beta$-lactam agents, with and without an extended spectrum, have been studied in combination with heparin and form stable locking solutions. Aminoglycosides and vancomycin have been studied with different additives such as heparin, citrate, and tissue plasminogen activator (TPA). ${ }^{61}$ In the NICU population, there is insufficient evidence for the effectiveness and safety of citrate locking solutions, although some institutions use sodium citrate $4 \%$ as the anticoagulant in the antimicrobial locks in combination with antimicrobial agents such as cefepime, vancomycin, or gentamicin. ${ }^{62}$

The safety and efficacy of ethanol locks have not been studied in NICU patients, but limited data exist on their use in infants with intestinal failure ${ }^{63}$ as young as 0.3 years and who weigh at least 5 kilograms. ${ }^{64-70}$ A recent systematic review and meta-analysis concluded that prophylactic ethanol locks in patients with intestinal failure reduced CLABSIs and catheter replacements but were associated with an increased need for catheter repair. ${ }^{71}$ The potential for alcohol-related toxicity was also assessed in a pilot study that enrolled 10 infants (mean age, 3.5 months; mean weight, 4.5 $\mathrm{kg}$ ). Blood-alcohol concentrations were assessed 1 hour after a $0.4 \mathrm{~mL}$ dose of ethanol was flushed through the CVC, equivalent to the volume that would be used during ethanol lock therapy. ${ }^{72} \mathrm{At}$ 
Table 5. Examples of Antimicrobial Locks ${ }^{96}$

\begin{tabular}{|c|c|c|c|c|c|c|c|}
\hline Antimicrobial Lock Therapy & Vial Concentration & Vol. $1 \mathrm{~mL}$ & Vol. $2 \mathrm{~mL}$ & Vol. $3 \mathrm{~mL}$ & Vol. $5 \mathrm{~mL}$ & Final Concentration & Stability \\
\hline \multirow{4}{*}{ Vancomycin } & Vancomycin $50 \mathrm{mg} / \mathrm{mL}$ vial & 0.2 & 0.4 & 0.6 & 1.0 & $10 \mathrm{mg} / \mathrm{mL}$ & \multirow{4}{*}{7 days refrigerated } \\
\hline & $0.9 \%$ normal saline (NS) & 0.8 & 1.6 & 2.4 & 4.4 & & \\
\hline & $\begin{array}{l}\text { Vancomycin } 5 \mathrm{mg} / \mathrm{mL} \text { solution } \\
\text { (dilute with } \mathrm{NS} \text { ) }\end{array}$ & 0.5 & 1.0 & 1.5 & 2.5 & $2.5 \mathrm{mg} / \mathrm{mL}$ & \\
\hline & Heparin 100 units $/ \mathrm{mL}$ & 0.5 & 1.0 & 1.5 & 2.5 & 50 units $/ \mathrm{mL}$ & \\
\hline \multirow[t]{2}{*}{ Gentamicin } & Gentamicin $10 \mathrm{mg} / \mathrm{mL}$ vial & 0.5 & 1.0 & 1.5 & 2.5 & $5 \mathrm{mg} / \mathrm{mL}$ & \multirow[t]{2}{*}{7 days refrigerated } \\
\hline & $0.9 \%$ NS & 0.5 & 1.0 & 1.5 & 2.5 & & \\
\hline \multirow[t]{3}{*}{ Ceftazidime } & Ceftazidime $100 \mathrm{mg} / \mathrm{mL}$ vial & 0.1 & 0.2 & 0.3 & 0.5 & $10 \mathrm{mg} / \mathrm{mL}$ & \multirow[t]{3}{*}{7 days refrigerated } \\
\hline & Heparin 100 units/mL & 0.5 & 1.0 & 1.5 & 2.5 & 50 units/mL & \\
\hline & $0.9 \%$ NS & 0.4 & 0.8 & 1.2 & 2.0 & - & \\
\hline \multirow[t]{2}{*}{ Amphotericin $\mathrm{B}^{*}$} & Amphotericin B $5 \mathrm{mg} / \mathrm{mL}$ vial & 0.5 & 1.0 & 1.5 & 2.5 & $2.5 \mathrm{mg} / \mathrm{mL}$ & \multirow[t]{2}{*}{7 days refrigerated } \\
\hline & Heparin 100 units $/ \mathrm{mL}$ & 0.5 & 1.0 & 1.5 & 2.5 & 50 units $/ \mathrm{mL}$ & \\
\hline
\end{tabular}

*Rarely used since removal of catheter is recommended in the setting of fungemia.

5 minutes, 8 patients had undetectable blood alcohol concentrations and 2 patients had alcoholaemia of $0.011 \%$. At 1 hour, blood alcohol concentrations were undetectable in all infants and there was no evidence of hepatic injury. No data are available on the repeated use of ethanol locks in the neonatal population. The cost and general availability of ethanol lock solutions many limit their potential use.

Practical guidance for implementation when the decision is made to use antimicrobial lock therapy is presented in Table 6.

Question 8: Should prophylactic antimicrobials be administered to a NICU patient at the time of PICC removal to reduce the incidence of CLABSI or culture-positive sepsis?

\section{Answer 8:}

- Prophylactic antimicrobials are not recommended at the time of PICC removal.

The proposed rationale for prophylactic antimicrobials administered to NICU patients at the time of PICC removal is to mitigate the potential impact of dislodgement of intra- or extra-luminal bacterial biofilm and subsequent bacteremia that elevates the frequency of BSI or culture-positive sepsis in the days following catheter removal. The actual risk of BSI following catheter removal is not well described. One single-center, retrospective, cohort study of 101 preterm infants did not identify an increased risk of catheter-related BSI in the 48 hours following removal of PICCs. ${ }^{73} \mathrm{~A}$ second retrospective cohort study that included 1,002 PICCs in 856 infants did not find a difference in the prevalence of BSIs or culture-negative sepsis when comparing the 72 hours before PICC removal to the 72 hours after removal. ${ }^{74}$ However, for infants with birth weight $<1,500$ grams, the odds for culture-negative sepsis increased 6.3-fold following removal of PICC not used for antimicrobial delivery $(95 \% \mathrm{CI}, 1.78-26.86 ; P<.01) .{ }^{74} \mathrm{~A}$ third retrospective cohort study conducted before the widespread implementation of CVC insertion and maintenance bundles reported a high rate of culture-positive sepsis within 5 days of PICC removal ( 24 of $345,7 \%) .{ }^{75}$ The incidence of sepsis was lower in infants who received antimicrobials at the time of catheter removal: $2(1.5 \%)$ of 132 versus $22(10.3 \%)$ of $213(P=.002)$.
Subsequent studies have not demonstrated a benefit to prophylactic antimicrobials before PICC removal. One retrospective study identified no difference in clinical or culture-positive sepsis in 137 infants who received a single dose of vancomycin before PICC removal and 64 infants who received no antimicrobial. ${ }^{76}$ In a second retrospective cohort study of 216 NICU patients with PICCs, the occurrence of microbiologically proven $(n=6)$ or clinical sepsis $(n=8)$ was uncommon within 5 days of catheter removal, and no benefit was identified with antimicrobial use at the time of PICC removal (OR, 0.6; 95\% CI, 0.1-2.7; $P=.74$ ). ${ }^{77}$ A single randomized, unblinded trial enrolled 88 infants who received intravenous cefazolin administered 1 hour before or 12 hours after catheter removal. ${ }^{78}$ Although the authors reported a difference in culture-positive sepsis within 48 hours ( $0 \%$ of treated infants vs $11 \%$ of controls, $P=.021$ ), there were significant methodological issues, and subsequent analyses suggested that this difference was not statistically significant (RR, 0.09; 95\% CI, 0.011.60). ${ }^{79,80}$ No studies have systematically evaluated potential harms of antimicrobial prophylaxis at the time of catheter removal, such as impact on the neonatal microbiome. A 2018 Cochrane review concluded that there is insufficient evidence to assess the efficacy or safety of antimicrobials given at the time of catheter removal. ${ }^{79}$

Question 9: What are practical considerations for the implementation of a neonatal vascular access team (VAT)?

\section{Answer 9:}

- NICUs should consider use of a VAT. Such teams have demonstrated effectiveness in reducing catheter-related complications and are cost-effective. ${ }^{22,81-83}$

- VAT proceduralists should receive education and clinical training, and upon completion, demonstrate knowledge and proficiency in PICC insertion, care, and removal, and a commitment to the team-based approach.

- VAT proceduralists should successfully insert a predefined number of PICCs as defined by the local facility's delineation of privileges.

- The team should monitor relevant quality measures (see Table 7). 
Table 6. Antimicrobial Lock Implementation

Instilling an Antimicrobial Lock

1. Order the antimicrobial lock therapy through the electronic medical record system, if used in the facility, to avoid errors

2. Obtain pharmacy-dispensed volume-specific syringes for each lumen

3. Prepare for:

a. 4 hours of dwell time (optimal)

b. Changing all line locks solutions inserted into ports every 24 hours

4. Flush each lumen with $0.9 \%$ sodium chloride before instilling the antimicrobial lock

5. At the end of the dwell time, withdraw the instilled antimicrobial lock priming volume and discard. Some institutions will withdraw an additional $0.1 \mathrm{~mL}$, or an additional percentage of the total volume

6. After removing and discarding the lock, flush the lumen(s) with $0.9 \%$ sodium chloride before infusion of other medications or fluids through the line

7. If patient is being transferred to a procedure area (line may be accessed), withdraw all lock solutions prior to patient leaving the unit

8. Obtain VAT evaluation and intervention if unable to withdraw antimicrobial lock from any lumen

\section{Assessing Fill or Priming Volume of Existing CVCs}

1. Perform hand hygiene

2. Disinfect cap/lumen connection with hospital-approved antiseptic

3. Clamp the lumen and remove existing needleless access device from the CVC hub of the lumen

4. Attach empty $3 \mathrm{~mL}$ luer-lock syringe directly to the hub of the lumen

5. Aspirate plunger slowly and gently until blood reaches the end of the hub

6. Clamp the line

7. Remove the syringe: the volume of fluid in the $3 \mathrm{~mL}$ syringe is the volume to be used for the lock volume

8. Flush the line

Table 7. Neonatal Vascular Access Team (VAT) Training, Evaluation, and Responsibilities ${ }^{15}$

\begin{tabular}{|c|c|}
\hline $\begin{array}{l}\text { After receiving training, who may be a proceduralist on a } \\
\text { Neonatal VAT? }\end{array}$ & $\begin{array}{l}\text { Neonatal nurse practitioners, registered nurses (in accordance with State Board of Nursing } \\
\text { scope of practice), neonatal fellows with appropriate supervision, neonatologists }\end{array}$ \\
\hline $\begin{array}{l}\text { What should clinical training and education for } \\
\text { proceduralists include? }\end{array}$ & $\begin{array}{l}\text { - Indications and contraindications of PICC placement } \\
\text { - Increased awareness of pain management } \\
\text { - Knowledge of the anatomy of venous and arterial systems } \\
\text { - Maintenance of the sterile insertion bundle }\end{array}$ \\
\hline $\begin{array}{l}\text { What knowledge and clinical competencies should a } \\
\text { proceduralist be able to demonstrate after training? }\end{array}$ & $\begin{array}{l}\text { - Knowledge of published guidelines and standards of infusion therapy } \\
\text { - Appropriate catheter care and maintenance } \\
\text { - Ability to recognize and manage complications } \\
\text { - Successful placement of at least } 5 \text { PICC lines }\end{array}$ \\
\hline $\begin{array}{l}\text { How many procedures should a proceduralist perform to } \\
\text { maintain competency? }\end{array}$ & $\begin{array}{l}\text { Proceduralists should consistently perform a requisite number of procedures, as defined by } \\
\text { the local facility's delineation of privileges. At a minimum, a proceduralist should perform } 5 \\
\text { successful PICC insertions per year }\end{array}$ \\
\hline $\begin{array}{l}\text { What are examples of quality measures that a VAT should } \\
\text { monitor? }\end{array}$ & $\begin{array}{l}\text { - Success rate of individual proceduralists } \\
\text { - Rates of complications (CLABSI, thrombus, pericardial and pleural effusions, etc.) } \\
\text { - Confirmation of final line location via radiographic imaging or point-of-care ultrasound }\end{array}$ \\
\hline What additional responsibilities might a VAT handle? & $\begin{array}{l}\text { - Troubleshooting and managing complications } \\
\text { - Providing formal and informal staff education related to care and maintenance of central } \\
\text { lines } \\
\text { - Performing catheter site surveillance and dressing changes } \\
\text { - Discussing removal of PICC line when patient reaches } 120 \mathrm{ml} / \mathrm{kg} / \mathrm{day} \text { of enteral intake }{ }^{97}\end{array}$ \\
\hline
\end{tabular}

This document defines VAT as any organized group of HCP involved in the management of vascular access. Prevention of CLABSIs benefits from the establishment of a team dedicated to all aspects of intravenous therapy. A recommendation of the Consensus Conference on Prevention of Central-LineAssociated Bloodstream Infections was the establishment of dedicated intravenous therapy teams, citing studies that showed reductions in infections and complications from central and peripheral intravenous catheters. ${ }^{84}$ In practice, the duties of VATs toward the catheters they care for vary by institution. The authors suggest that the VAT's responsibilities include catheter insertion, daily inspection, and maintenance, as well as development and education related to policies and procedures. A dedicated team with expertise in PICC assessment, placement, and care can serve as an invaluable resource for the NICU. The VAT also can provide information to infection preventionists in the form of data collection and identification of trends to inform quality improvement efforts. Including the team members in infection prevention meetings will assist in guiding the focus of prevention during insertion of the PICC. Duties may also include investigation of positive blood cultures, in conjunction with the healthcare epidemiology and infection prevention teams. ${ }^{85}$ This places the focus of the team on prevention rather than just job duties. In one medical center, including a VAT as part of a "better bundle" strategy was associated with a significant decrease in CLABSIs. ${ }^{85}$ Published guidelines state 
that specialized "IV teams," such as the VAT, have shown unequivocal effectiveness in reducing the incidence of catheter-related BSI (CR-BSI), associated complications, and costs. ${ }^{81}$

Proper sterile technique during the placement of CVCs remains paramount for reduction of CLABSIs. Standardization of procedures for long-term maintenance of CVCs helps to reduce the incidence of CLABSIs in intensive-care patients. ${ }^{86}$ An identified VAT allows organizations to centralize the responsibility for PICCrelated activities with a select group of proceduralists, thus enhancing accountability and ultimately, clinical outcomes. ${ }^{83}$ The upfront investment in a VAT results in cost savings from a reduction in the number of CLABSIs and other CVC-related complications. In one NICU, the initiation of a dedicated PICC insertion and maintenance team resulted in a nearly 50\% decrease in the risk of CLABSI in patients who required long-term central venous access (ie, $>30$ days).$^{87}$

Additionally, by developing a VAT, a facility may reduce the resources spent training and retraining proceduralists and ancillary support staff in central-line insertion and maintenance. ${ }^{21}$ Regardless, standards for the training of proceduralists vary. A recent national survey showed that most proceduralists attend informal training sessions, with less stringent training requirements for physicians than registered nurses or nurse practitioners. $^{88}$ Many of proceduralists have $<5$ successful placements before being allowed to insert a PICC independently. Table 7 provides a list of recommended education, training, and competencies for members of a neonatal VAT.

Question 10: What threshold should prompt a NICU to consider implementing additional preventive measures?

Answer 10:

- Zero CLABSIs is the aspirational and potentially achievable goal. Although there is no nationally endorsed threshold above which additional CLABSI prevention measures should be implemented, a variety of quantitative or qualitative metrics may be utilized to identify CLABSI prevention success over time and determine when additional intervention is necessary.

- A decision to identify a threshold for action in an individual NICU should assess a variety of factors including the following:

- An SIR or rate of CLABSI that is above goal or increasing despite the consistent implementation of current organizational interventions

- Local interest in setting a specific lower target with input from Infection Prevention and Control (infection preventionists, healthcare epidemiologist)

- Patient mix and clinical acuity, which may predict general likelihood of CLABSI

- Resource and personnel capacity for initiation and/or maintenance of specific interventions and practice processes.

- Any quantitative or qualitative metric that is defined should be developed and accepted by all stakeholders.

CLABSI prevention should be a continuous goal and integrated into usual NICU practices and processes. Successful CLABSI prevention requires attention to the importance of practices related to central-line insertion and maintenance over time and collaboration among a variety of stakeholders, including infection preventionists, nurses, physicians, advanced practice HCP, and educators, among others. The decision to increase infection prevention efforts requires the involvement of NICU leadership or a local champion to ensure that new processes and education are prioritized within existing workflows. Individual units have achieved very low rates of CLABSIs-even zero CLABSIs-over sustained periods. ${ }^{6,22}$

A variety of quantitative metrics can be used to reveal a lapse in CLABSI prevention success. Quantitative metrics may include total NICU-wide CLABSI incidence over a predefined period, compared to a similar period that allows for adjustment for time-varying confounders (eg, season, census, staff shortages, and turnover). Alternatively, an absolute number of CLABSIs may be deemed "acceptable" in a particular NICU for a given period or a given patient census. Either of these metrics also may be considered for a subset of high-risk infants as a marker for general CLABSI prevention effectiveness (eg, postoperative patients, premature infants, and others). Lastly, a NICU may consider a predefined target standard infection ratio (SIR), a risk-adjusted metric generated by the CDC using NICUspecific surveillance data reported to NHSN (eg, SIR < 1.0). ${ }^{89}$

NICUs may also choose to increase CLABSI prevention efforts based upon rigorously evaluated or even anecdotal qualitative observations in the unit. Qualitative observations can be performed actively on an ad hoc basis or via routine mechanisms such as team huddles with checklists or overt comprehensive audits of any or all practices. Real-time perceptions among staff of waning vigilance toward CVC maintenance practices or repeated breaches in protocol for specific practices related to line insertion or maintenance must be taken seriously and properly investigated. Ultimately, any developed target metric that may trigger more intensive CLABSI prevention efforts should be acceptable to all a priori, particularly those involved with CVC use and CLABSI prevention at the bedside.

Before a decision is made to introduce new processes for CLABSI prevention, it is important to assess the adherence to existing prevention practices in the NICU in a systematic fashion, for example, through a quality improvement (QI) program. Such assessments should include direct input from infection preventionists, nurses, advance practice HCP, and physicians. If additional CLABSI measures are deemed necessary, it is helpful to distinguish between those shown to be effective and those that are not proven robustly but may have an impact nonetheless. Known effective evidence-based interventions have been identified by the CDC and other experts (Table 3). ${ }^{8,17}$

If an effort to enhance CLABSI prevention activities is deemed necessary, it must be recognized that staff at various levels of responsibility may have different attitudes or willingness to add tasks to the workflow. ${ }^{90}$ Simply having a written policy is insufficient to effect practice change(s) that will lead to fewer CLABSIs. In 2011 , a national survey noted that $84 \%-93 \%$ of NICUs had written policies for insertion checklist and for bundle practices, but $\geq 75 \%$ adherence for individual components was achieved only $68 \%-73 \%$ of the time for at least 1 component and only $28 \%$ for all monitored processes. ${ }^{91}$ Allowance for adaptations (dependent on local workflows and priorities) is important, and quantitative metrics should be used as a guide to effectiveness. ${ }^{92}$

Question 11: What preventive bundle elements, above and beyond those recommended by the $\mathrm{CDC}$, could be considered by a NICU experiencing ongoing CLABSIs?

\section{Answer 11:}

- Additional practices that lack robust evidence may be effective. NICUs may consider many different products, technologies, and processes, some of which are described below. 
- Implementation of an expanded NICU central-line care bundle should take into account the risks and benefits of additional measures, as well as the needs, resources, and local expertise at individual institutions.

- If implemented, the impact of these practices should be evaluated by a multidisciplinary team.

Evidence-based care bundles effectively reduce CLABSIs in the NICU. A meta-analysis performed by Payne et $\mathrm{al}^{4}$ reported a $60 \%$ decrease in CLABSI rates after the introduction of a care bundle in neonatal units. Additionally, care bundles contribute to a reduction in total central-line use and duration. The CDC has recommended basic insertion and maintenance bundles for all patients with CVCs, including NICU patients (Table 3). Nevertheless, published reports suggest substantial variability in bundles utilized in NICUs and little consensus about what constitutes the optimal bundle. A variety of CLABSI prevention bundles with different individual components have been shown to minimize CLABSIs in NICU settings, although most include hand hygiene, maximal sterile barrier precautions, and effective skin antisepsis. ${ }^{93}$ Few studies have compared the effectiveness of different bundles in a way that permits assessment of individual bundle components.

Throughout this document, we have reviewed practices and products that could be added to basic prevention bundles, including CHG bathing, CHG-containing sponges at central-line insertion sites, ethanol disinfectant caps, and prophylactic antimicrobial locks. Additional practices may be effective and have been implemented by some NICUs, but they lack robust evidence and therefore have not been reviewed in detail in these recommendations. Such practices include but are not limited to regular sharing of CLABSI incidence data with NICU staff, the use of nonsterile gloves for all central-line care, ${ }^{94}$ and a standard process for assessing when to discontinue a central line, such as when the infant is tolerating full enteral feeds and medications can be provided enterally. ${ }^{22,95}$ For the assessment of continued need or discontinuation of a CVC, a short checklist in the daily note of the nurse or physician with discussion on multidisciplinary patient rounds may be a useful tool.

Most studies of bundle effectiveness have been conducted in larger, higher level-of-care NICUs. Similar effectiveness is anticipated in community NICUs that care for infants with CVCs.

Acknowledgments. The authors wish to thank NICU Advisory Panel Chairs, Drs. Alexis Elward and Deborah Yokoe. The authors thank Valerie Deloney, MBA and John Heys for their organizational expertise in the development of this manuscript.

NICU Advisory Panel : Kenneth M. Zangwill, MD, American Academy of Pediatrics Section on Infectious Diseases (AAP/SOID); Nancy Foster, American Hospital Association (AHA); Jessica R. Rindels, MBA, BSN, RN, CIC, Association for Professionals in Infection Control and Epidemiology (APIC); Jill Jones MS, APRN, NNP-BC, National Association of Neonatal Nurses (NANN); Pablo J. Sánchez, MD, Infectious Diseases Society of America (IDSA); Aaron M. Milstone, MD, Pediatric Infectious Diseases Society (PIDS); Margaret VanAmringe, MHS, The Joint Commission; Judith Guzman-Cottrill, DO, The Vermont Oxford Network (VON).

Conflicts of interest. The following disclosures are a reflection of what has been reported to SHEA. To provide thorough transparency, SHEA requires full disclosure of all relationships, regardless of relevancy to the guideline topic. Evaluation of such relationships as potential conflicts of interest is determined by a review process.

The assessment of disclosed relationships for possible conflicts of interest will be based on the relative weight of the financial relationship (ie, monetary amount) and the relevance of the relationship (ie, the degree to which an association might reasonably be interpreted by an independent observer as related to the topic or recommendation of consideration). The reader of this guidance should be mindful of this when the list of disclosures is reviewed.

K.A.B. reports being a principal investigator on multicenter clinical trials funded by Pfizer, Gilead, and Enanta (payments made to institution) and serving as Immediate Past President of the Pediatric Infectious Diseases Society. P.J.S. reports a grant for institution support from Merck (completed prior to publication) and current participation on the CDC Advisory Committee on Immunization Practices (ACIP). All other authors report no conflicts of interest relevant to this article.

\section{References}

1. Stoll BJ, Hansen NI, Adams-Chapman I, et al. Neurodevelopmental and growth impairment among extremely low-birth-weight infants with neonatal infection. JAMA 2004;292:2357-2365.

2. Bright HR, Babata K, Allred EN, et al. Neurocognitive outcomes at 10 years of age in extremely preterm newborns with late-onset bacteremia. J Pediatr 2017;187:43-49.

3. Bakhuizen SE, de Haan TR, Teune MJ, et al. Meta-analysis shows that infants who have suffered neonatal sepsis face an increased risk of mortality and severe complications. Acta Paediatr 2014;103:1211-1218.

4. Payne NR, Barry J, Berg W, et al. Sustained reduction in neonatal nosocomial infections through quality improvement efforts. Pediatrics 2012;129: e165-e173.

5. Schulman J, Stricof R, Stevens TP, et al. Statewide NICU central-line-associated bloodstream infection rates decline after bundles and checklists. Pediatrics 2011;127:436-444.

6. Shepherd EG, Kelly TJ, Vinsel JA, et al. Significant reduction of central-lineassociated bloodstream infections in a network of diverse neonatal nurseries. J Pediatr 2015;167:41-46.

7. Hsu HE, Mathew R, Wang R, et al. Healthcare-associated infections among critically ill children in the US, 2013-2018. JAMA Pediatr 2020;174:11761183.

8. Checklist for prevention of central-line-associated blood stream infections. Centers for Disease Control and Prevention website. https://www.cdc.gov/ hai/pdfs/bsi/checklist-for-clabsi.pdf. Accessed March 9, 2022.

9. Recommendations for prevention and control of infections in neonatal intensive care unit patients: central-line-associated bloodstream infections. Centers for Disease Control and Prevention website. https://www.cdc.gov/ infectioncontrol/guidelines/nicu-clabsi/recommendations.html. Published 2022. Accessed March 10, 2022.

10. Guyatt GH, Oxman AD, Vist GE, et al. GRADE: an emerging consensus on rating quality of evidence and strength of recommendations. $B M$ J 2008;336:924-926.

11. Sandora TJ, Bryant KK, Cantey JB, Elward AM, Yokoe DS, Bartlett AH. SHEA neonatal intensive care unit (NICU) white paper series: practical approaches to Clostridioides difficile prevention. Infect Control Hosp Epidemiol 2018;39:1149-1153.

12. Akinboyo IC, Zangwill KM, Berg WM, Cantey JB, Huizinga B, Milstone AM. SHEA neonatal intensive care unit (NICU) white paper series: practical approaches to Staphylococcus aureus disease prevention. Infect Control Hosp Epidemiol 2020;41:1251-1257.

13. US Department of Health and Human Services. Supplemental new drug application. NDA 020832 ChloraPrep [chlorhexidine gluconate $(2 \% \mathrm{w} / \mathrm{v})$ and isopropyl alcohol $(70 \% \mathrm{v} / \mathrm{v})]$ solution; NDA 021555 ChloraPrep [chlorhexidine gluconate $(2 \% \mathrm{w} / \mathrm{v})$ and isopropyl alcohol $(70 \% \mathrm{v} / \mathrm{v})]$ solution, 2012. US Food and Drug Administration website. https://www.accessdata.fda.gov/drugsatfda docs/appletter/2012/020832Origs030,021555Orig1s017ltr.pdf. Accessed March 9, 2022.

14. Sharma A, Kulkarni S, Thukral A, et al. Aqueous chlorhexidine $1 \%$ versus $2 \%$ for neonatal skin antisepsis: a randomised noninferiority trial. Arch Dis Child Fetal Neonatal Ed 2021;106:643-648.

15. Garland JS, Alex CP, Uhing MR, Peterside IE, Rentz A, Harris MC. Pilot trial to compare tolerance of chlorhexidine gluconate to povidone-iodine antisepsis for central venous catheter placement in neonates. J Perinatol 2009;29:808-813. 
16. Johnson J, Bracken R, Tamma PD, Aucott SW, Bearer C, Milstone AM. Trends in chlorhexidine use in US neonatal intensive care units: results from a follow-up national survey. Infect Control Hosp Epidemiol 2016;37:11161118.

17. Buetti N, Marschall J, Drees M, et al. Strategies to prevent central line-associated bloodstream infections in acute-care hospitals: 2022 Update. Infect Control Hosp Epidemiol 2022;1-17 doi: 10.1017/ice.2022.87.

18. Kieran EA, O'Sullivan A, Miletin J, Twomey AR, Knowles SJ, O'Donnell CPF. 2\% chlorhexidine-70\% isopropyl alcohol versus $10 \%$ povidone-iodine for insertion site cleaning before central-line insertion in preterm infants: a randomised trial. Arch Dis Child Fetal Neonatal Ed 2018;103:F101-F106.

19. Neri I, Ravaioli GM, Faldella G, Capretti MG, Arcuri S, Patrizi A. Chlorhexidine-induced chemical burns in very low birth weight infants. $J$ Pediatr 2017;191:262-265.

20. Paternoster M, Niola M, Graziano V. Avoiding chlorhexidine burns in preterm infants. J Obstet Gynecol Neonatal Nurs 2017;46:267-271.

21. Preventing central-line-associated bloodstream infections: useful tools, an international perspective. The Joint Commission website. www. jointcommission.org/CLABSI/Toolkit. Published 2013. Accessed August 29, 2021.

22. Mobley RE, Bizzarro MJ. Central-line-associated bloodstream infections in the NICU: Successes and controversies in the quest for zero. Semin Perinatol 2017;41:166-174.

23. Bizzarro MJ, Sabo B, Noonan M, et al. A quality improvement initiative to reduce central-line-associated bloodstream infections in a neonatal intensive care unit. Infect Control Hosp Epidemiol 2010;31:241-248.

24. D’Andrea V, Pezza L, Barone G, Prontera G, Pittiruti M, Vento G. Use of cyanoacrylate glue for the sutureless securement of epicutaneo-caval catheters in neonates. J Vasc Access 2021. doi: 10.1177/11297298211008103.

25. Bryant KA, Guzman-Cottrill JA, editors. Handbook of Pediatric Infection Prevention and Control. Oxford, UK: Oxford University Press; 2019.

26. NICE. Biopatch for venous or arterial catheter sites: Medtech innovation briefing (MIB117): National Institute for Health and Care Excellence (NICE) website. www.nice.org.uk/guidance/mib117. Updated August 9, 2017. Accessed December 2021.

27. Miller MR, Niedner MF, Huskins WC, et al. Reducing PICU central-lineassociated bloodstream infections: 3-year results. Pediatrics 2011;128: e1077-e1083.

28. Southern West Midlands Newborn Network. Broviac lines for central venous access: a guide for neonatal staff. US National Health Service website. https:/www.networks.nhs.uk/nhs-networks/southern-west-midlandsnewborn-network/documents/Attachment\%2014\%20SWMNN\%20Broviac \%20lines\%202012.pdf. Accessed March 10, 2022.

29. Lai NM, Taylor JE, Tan K, Choo YM, Ahmad Kamar A, Muhamad NA. Antimicrobial dressings for the prevention of catheter-related infections in newborn infants with central venous catheters. Cochrane Database Syst Rev 2016;3:CD011082.

30. SHEA. Neonatal intensive care unit (NICU) survey on infection prevention practices. Unpublished; 2014.

31. Wright MO, Tropp J, Schora DM, et al. Continuous passive disinfection of catheter hubs prevents contamination and bloodstream infection. Am J Infect Control 2013;41:33-38.

32. Sauron C, Jouvet P, Pinard G, et al. Using isopropyl alcohol impregnated disinfection caps in the neonatal intensive care unit can cause isopropyl alcohol toxicity. Acta Paediatr 2015;104:e489-e493.

33. Hjalmarsson LB, Hagberg J, Schollin J, Ohlin A. Leakage of isopropanol from port protectors used in neonatal care-results from an in vitro study. PLoS One 2020;15:e235593.

34. O'Connell S, Dale M, Morgan H, Carter K, Carolan-Rees G. Curos disinfection caps for the prevention of infection when using needleless connectors: A NICE medical technologies guidance. Appl Health Econ Health Policy 2021;19:145-153.

35. Voor In't Holt AF, Helder OK, Vos MC, et al. Antiseptic barrier cap effective in reducing central-line-associated bloodstream infections: a systematic review and meta-analysis. Int J Nurs Stud 2017;69:34-40.

36. Helder OK, van Rosmalen J, van Dalen A, et al. Effect of the use of an antiseptic barrier cap on the rates of central-line-associated bloodstream infections in neonatal and pediatric intensive care. Am J Infect Control 2020;48:1171-1178.

37. Milstone AM, Rosenberg C, Yenokyan G, Koontz DW, Miller MR, Group CA. Alcohol-impregnated caps and ambulatory central-line-associated bloodstream infections (CLABSIs): a randomized clinical trial. Infect Control Hosp Epidemiol 2021;42:431-439.

38. Chapman AK, Aucott SW, Milstone AM. Safety of chlorhexidine gluconate used for skin antisepsis in the preterm infant. J Perinatol 2012;32:4-9.

39. Milstone AM, Elward A, Song X, et al. Daily chlorhexidine bathing to reduce bacteraemia in critically ill children: a multicentre, cluster-randomised, crossover trial. Lancet 2013;381:1099-1106.

40. Johnson J, Suwantarat N, Colantuoni E, et al. The impact of chlorhexidine gluconate bathing on skin bacterial burden of neonates admitted to the neonatal intensive care unit. J Perinatol 2019;39:63-71.

41. Sankar MJ, Paul VK, Kapil A, et al. Does skin cleansing with chlorhexidine affect skin condition, temperature and colonization in hospitalized preterm low birth weight infants? A randomized clinical trial. J Perinatol 2009;29:795-801.

42. Quach C, Milstone AM, Perpete C, Bonenfant M, Moore DL, Perreault T. Chlorhexidine bathing in a tertiary-care neonatal intensive care unit: impact on central-line-associated bloodstream infections. Infect Control Hosp Epidemiol 2014;35:158-163.

43. Cleves D, Pino J, Patino JA, Rosso F, Velez JD, Perez P. Effect of chlorhexidine baths on central-line-associated bloodstream infections in a neonatal intensive care unit in a developing country. J Hosp Infect 2018;100:e196-e199.

44. Milstone AM, Bamford P, Aucott SW, Tang N, White KR, Bearer CF. Chlorhexidine inhibits L1 cell adhesion molecule-mediated neurite outgrowth in vitro. Pediatr Res 2014;75:8-13.

45. Suwantarat N, Carroll KC, Tekle T, et al. High prevalence of reduced chlorhexidine susceptibility in organisms causing central-line-associated bloodstream infections. Infect Control Hosp Epidemiol 2014;35: 1183-1186.

46. Maki DG, Rosenthal VD, Salomao R, Franzetti F, Rangel-Frausto MS. Impact of switching from an open to a closed infusion system on rates of central-lineassociated bloodstream infection: a meta-analysis of time-sequence cohort studies in 4 countries. Infect Control Hosp Epidemiol 2011;32:50-58.

47. Mahieu LM, De Dooy JJ, Lenaerts AE, Ieven MM, De Muynck AO. Catheter manipulations and the risk of catheter-associated bloodstream infection in neonatal intensive care unit patients. J Hosp Infect 2001;48:20-26.

48. Dahan M, O'Donnell S, Hebert J, et al. CLABSI risk factors in the NICU: potential for prevention: a PICNIC study. Infect Control Hosp Epidemiol 2016;37:1446-1152.

49. Klunk CJ, Barrett RE, Peterec SM, et al. An initiative to decrease laboratory testing in a NICU. Pediatrics 2021;148.

50. Coggins SA, Harris MC, Srinivasan L. Dual-site blood culture yield and time to positivity in neonatal late-onset sepsis. Arch Dis Child Fetal Neonatal Ed 2021. doi: 10.1136/archdischild-2021-322844.

51. Miller JM, Binnicker MJ, Campbell S, et al. A guide to utilization of the microbiology laboratory for diagnosis of infectious diseases: 2018 update by the Infectious Diseases Society of America and the American Society for Microbiology. Clin Infect Dis 2018;67:813-816.

52. Woods-Hill CZ, Colantuoni EA, Koontz DW, et al. Association of diagnostic stewardship for blood cultures in critically ill children with culture rates, antibiotic use, and patient outcomes: results of the bright STAR collaborative. JAMA Pediatr 2022. doi: 10.1001/jamapediatrics.2022.1024.

53. Woods-Hill CZ, Koontz DW, et al. Consensus recommendations for blood culture use in critically ill children using a modified Delphi approach. Pediatr Crit Care Med 2021;22:774-784.

54. Falagas ME, Kazantzi MS, Bliziotis IA. Comparison of utility of blood cultures from intravascular catheters and peripheral veins: a systematic review and decision analysis. J Med Microbiol 2008;57:1-8.

55. Tang M, Feng M, Chen L, Zhang J, Ji P, Luo S. Closed blood conservation device for reducing catheter-related infections in children after cardiac surgery. Crit Care Nurse 2014;34:53-60.

56. Oto J, Nakataki E, Hata M, et al. Comparison of bacterial contamination of blood conservation system and stopcock system arterial sampling lines used in critically ill patients. Am J Infect Control 2012;40:530-534. 
57. Benedict A, Mayer A, Craven H. Closed arterial lab sampling devices: a study of compliance and best practice. Br J Nurs 2017;26:S24-S29.

58. Filippi L, Pezzati M, Di Amario S, Poggi C, Pecile P. Fusidic acid and heparin lock solution for the prevention of catheter-related bloodstream infections in critically ill neonates: a retrospective study and a prospective, randomized trial. Pediatr Crit Care Med 2007;8:556-562.

59. Garland JS, Alex CP, Henrickson KJ, McAuliffe TL, Maki DG. A vancomycin-heparin lock solution for prevention of nosocomial bloodstream infection in critically ill neonates with peripherally inserted central venous catheters: a prospective, randomized trial. Pediatrics 2005;116:e198-e205.

60. Seliem WA-H, Hesham; El-Nady, Ghada. Amikacin-heparin lock for prevention of catheter-related bloodstream infection in neonates with extended umbilical venous catheters use: a randomized controlled trial. $J$ Neonat Perinat Med 2010;3:33-41.

61. Justo JA, Bookstaver PB. Antibiotic lock therapy: review of technique and logistical challenges. Infect Drug Resist. 2014;7:343-363.

62. Cincinnati Children's Hospital Medical Center. Na citrate. CCHMC Pharmacy \& Therapeutics Policy. Cincinnati: CCHMC; 2021.

63. Abu-El-Haija M, Schultz J, Rahhal RM. Effects of 70\% ethanol locks on rates of central-line infection, thrombosis, breakage, and replacement in pediatric intestinal failure. J Pediatr Gastroenterol Nutr 2014;58:703-708.

64. Jones BA, Hull MA, Richardson DS, et al. Efficacy of ethanol locks in reducing central venous catheter infections in pediatric patients with intestinal failure. J Pediatr Surg 2010;45:1287-1293.

65. Ardura MI, Lewis J, Tansmore JL, Harp PL, Dienhart MC, Balint JP. Central catheter-associated bloodstream infection reduction with ethanol lock prophylaxis in pediatric intestinal failure: broadening quality improvement initiatives from hospital to home. JAMA Pediatr 2015;169:324-331.

66. Mouw E, Chessman K, Lesher A, Tagge E. Use of an ethanol lock to prevent catheter-related infections in children with short bowel syndrome. J Pediatr Surg 2008;43:1025-1029.

67. Cober MP, Kovacevich DS, Teitelbaum DH. Ethanol-lock therapy for the prevention of central venous access device infections in pediatric patients with intestinal failure. J Parenter Enteral Nutr 2011;35:67-73.

68. Pieroni KP, Nespor C, Ng M, et al. Evaluation of ethanol lock therapy in pediatric patients on long-term parenteral nutrition. Nutr Clin Pract 2013;28:226-231.

69. Wales PW, Kosar C, Carricato M, de Silva N, Lang K, Avitzur Y. Ethanol lock therapy to reduce the incidence of catheter-related bloodstream infections in home parenteral nutrition patients with intestinal failure: preliminary experience. J Pediatr Surg 2011;46:951-956.

70. Mezoff EA, Fei L, Troutt M, Klotz K, Kocoshis SA, Cole CR. Ethanol lock efficacy and associated complications in children with intestinal failure. $J$ Parenter Enteral Nutr 2016;40:815-819.

71. Rahhal R, Abu-El-Haija MA, Fei L, et al. Systematic review and meta-analysis of the utilization of ethanol locks in pediatric patients with intestinal failure. J Parenter Enteral Nutr 2018;42:690-701.

72. Chhim RF, Crill CM, Collier HK, et al. Ethanol lock therapy: a pilot infusion study in infants. Ann Pharmacother 2015;49:431-436.

73. Brooker RW, Keenan WJ. Catheter-related bloodstream infection following PICC removal in preterm infants. J Perinatol 2007;27:171-174.

74. Casner M, Hoesli SJ, Slaughter JC, Hill M, Weitkamp JH. Incidence of catheter-related bloodstream infections in neonates following removal of peripherally inserted central venous catheters. Pediatr Crit Care Med 2014;15:42-48.

75. van den Hoogen A, Brouwer MJ, Gerards LJ, Fleer A, Krediet TG. Removal of percutaneously inserted central venous catheters in neonates is associated with the occurrence of sepsis. Acta Paediatr 2008;97:1250-1252.

76. Bhargava V, George L, Malloy M, Fonseca R. The role of a single dose of vancomycin in reducing clinical sepsis in premature infants prior to removal of peripherally inserted central catheter: a retrospective study. Am J Perinatol 2018;35:990-993.

77. Hoffman MA, Snowden JN, Simonsen KA, Nenninger TM, Lyden ER, Anderson-Berry AL. Neonatal late-onset sepsis following peripherally inserted central catheter removal: association with antibiotic use and adverse line events. J Infus Nurs 2015;38:129-134.

78. Hemels MA, van den Hoogen A, Verboon-Maciolek MA, Fleer A, Krediet TG. Prevention of neonatal late-onset sepsis associated with the removal of percutaneously inserted central venous catheters in preterm infants. Pediatr Crit Care Med 2011;12:445-448.

79. McMullan RL, Gordon A. Antibiotics at the time of removal of central venous catheter to reduce morbidity and mortality in newborn infants. Cochrane Database Syst Rev 2018;3:CD012181.

80. Degraeuwe PL, Kessels AG. The removal-associated sepsis prevention trial in preterm newborns was ended in an untimely manner. Pediatr Crit Care Med 2012;13:248-249.

81. Wyckoff MM, Sharpe EL. Peripherally Inserted Central Catheters: Guideline for Practice, Third Edition. Chicago: National Association of Neonatal Nurses; 2015.

82. Krein SL, Kuhn L, Ratz D, Chopra V. Use of designated nurse PICC teams and CLABSI prevention practices among US hospitals: a survey-based study. J Patient Saf 2019;15:293-295.

83. Stevens TP, Schulman J. Evidence-based approach to preventing centralline-associated bloodstream infection in the NICU. Acta Paediatr 2012;101:11-16.

84. Segreti J, Garcia-Houchins S, Gorski L, et al. Consensus conference on prevention of central-line-associated bloodstream infections: 2009. J Infus Nurs 2011;34:126-133.

85. Royer T. Implementing a better bundle to achieve and sustain a zero centralline-associated bloodstream infection rate. J Infus Nurs 2010;33:398-406.

86. Savage TJ, Lynch AD, Oddera SE. Implementation of a vascular access team to reduce central-line usage and prevent central-line-associated bloodstream infections. J Infus Nurs 2019;42:193-196.

87. Taylor T, Massaro A, Williams L, et al. Effect of a dedicated percutaneously inserted central catheter team on neonatal catheter-related bloodstream infection. Adv Neonatal Care 2011;11:122-128.

88. Sharpe E, Pettit J, Ellsbury DL. A national survey of neonatal peripherally inserted central catheter (PICC) practices. Adv Neonatal Care 2013;13:55-74.

89. National Healthcare Safety Network (NHSN). Bloodstream infection event (central-line-associated bloodstream infection and non-central-line-associated bloodstream infection). Centers for Disease Control and Prevention website. https://www.cdc.gov/nhsn/pdfs/pscmanual/4psc_clabscurrent.pdf. Published 2021. Accessed March 10, 2022.

90. Goldman J, Rotteau L, Shojania KG, et al. Implementation of a central-line bundle: a qualitative study of three clinical units. Implement Sci Commun 2021;2:105.

91. Zachariah P, Furuya EY, Edwards J, et al. Compliance with prevention practices and their association with central-line-associated bloodstream infections in neonatal intensive care units. Am J Infect Control 2014;42:847-851.

92. Mathew R, Simms A, Wood M, et al. Reduction of central-line-associated bloodstream infection through focus on the mesosystem: standardization, data, and accountability. Pediatr Qual Saf 2020;5:e272.

93. Paplawski S. Prevention of central-line-associated bloodstream infections in the neonatal intensive care unit: a literature review. J Neonatal Nurs 2020;26:142-148.

94. Kaufman DA, Blackman A, Conaway MR, Sinkin RA. Nonsterile glove use in addition to hand hygiene to prevent late-onset infection in preterm infants: randomized clinical trial. JAMA Pediatr 2014;168:909-916.

95. Payne V, Hall M, Prieto J, Johnson M. Care bundles to reduce central-lineassociated bloodstream infections in the neonatal unit: a systematic review and meta-analysis. Arch Dis Child Fetal Neonatal Ed 2018;103:F422-F429.

96. Antimicrobial lock therapy (ALT) organizational policies/guidelines. St Louis Children's Hospital website. https://www.stlouischildrens.org/health care-professionals/resources/clinical-resources/antimicrobial-stewardshipprogram-asp. Published December 2021. Accessed March 10, 2022.

97. Fisher D, Cochran KM, Provost LP, et al. Reducing central-line-associated bloodstream infections in North Carolina NICUs. Pediatrics 2013;132: e1664-e1671. 